\title{
Probiotics and prebiotics in infant nutrition
}

\author{
Helena Parracho, Anne L. McCartney and Glenn R. Gibson* \\ Food Microbial Sciences Unit, Department of Food Biosciences, The University of Reading, Whiteknights, PO Box 226, \\ Reading RG6 6AP, UK
}

\begin{abstract}
The human colonic microflora has a central role in health and disease, being unique in its complexity and range of functions. As such, dietary modulation is important for improved gut health, especially during the highly-sensitive stage of infancy. Diet can affect the composition of the gut microflora through the availability of different substrates for bacterial fermentation. Differences in gut microflora composition and incidence of infection exist between breast-fed and formula-fed infants, with the former thought to have improved protection. Historically, this improvement has been believed to be a result of the higher presence of reportedly-beneficial genera such as the bifidobacteria. As such, functional food ingredients such as prebiotics and probiotics could effect a beneficial modification in the composition and activities of gut microflora of infants by increasing positive flora components. The prebiotic approach aims to increase resident bacteria that are considered to be beneficial for human health, e.g. bifidobacteria and lactobacilli, while probiotics advocates the use of the live micro-organisms themselves in the diet. Both approaches have found their way into infant formula feeds and aim to more closely simulate the gut microbiota composition seen during breast-feeding.
\end{abstract}

Probiotics: Prebiotics: Gut microflora

At birth the gastrointestinal (GI) tract is essentially germfree, with initial colonisation occurring during birth or shortly afterwards. The GI tract of newborns is inoculated primarily by organisms that originate from the maternal microbial flora of the genital tract and colon and from the environment (e.g. through direct human contact and hospital surroundings; Holzapfel et al. 1998; Mountzouris et al. 2002). Bacterial populations develop during the first few days of life (Collins \& Gibson, 1999) and the intestinal flora develops as a result of the influence of intestinal physiology and diet on the acquired bacteria (Drasar \& Barrow, 1985).

Bacteria such as facultative Gram-positive cocci, enterobacteria and lactobacilli are the first colonisers. These micro-organisms rapidly consume any $\mathrm{O}_{2}$ that is present and subsequently create a more reduced environment, which then allows the growth of obligate anaerobic species (Rotimi \& Duerden, 1981). Marked differences in the composition of the gut flora have also been recognised in response to infant feeding regimens. The microflora of breast-fed infants is dominated by populations of bifidobacteria, which may explain the purported healthier outlook of breast-fed infants compared with their formula-fed counterparts (Harmsen et al. 2000). Formula-fed infants have a more complex microbiota, with bifidobacteria, bacteroides, lactobacilli, clostridia and streptococci all being prevalent (Stark \& Lee, 1982; Benno et al. 1984; Harmsen et al. 2000). It is thought that the presence of certain glycoproteins and soluble oligosaccharides in human breast milk is selectively stimulatory for bifidobacteria (Gauhe et al. 1954; Petschow \& Talbott, 1991). Moreover, human milk is also known to contain substantial amounts of oligosaccharides (i.e. lacto-N-tetraose and lacto-N-neotetraose). Certain of these oligosaccharides may act as soluble receptors in the mucosa for different pathogens, thus increasing the resistance of breast-fed infants (Kunz et al. 2000).

There is therefore a strong indication that diet can influence the relative amounts of microbial species and strains of the intestinal flora (Holzapfel et al. 1998). Following weaning these differences tend to disappear, the microflora increases in diversity and a community resembling the adult flora becomes established (Collins \& Gibson, 1999). The colonic microflora of infants is generally viewed as being adult-like after 2 years, although the levels of facultative anaerobes are reported to be higher than those in adults. Once the climax microbiota has become established, the major bacterial groups are 
relatively stable throughout most of adult life (Mitsuoka, 1992; Kimura et al. 1997; Macfarlane \& McBain, 1999).

Human breast milk is always seen as the preferred choice for infant nutrition (Cuthbertson, 1999). It is a wholly nutritious complete food for infants and contains many components that have important bioactive roles (Goldman et al. 1997; Garofalo \& Goldman, 1999). Whenever breast-feeding is not possible or not chosen, infant formulas are the alternatives. One approach to fortify the biological role of formula feeds has been to use probiotics and prebiotics as constituents. Here, the aim is to improve the gut microbiota composition to better resemble that seen with breast-feeding.

\section{Bacterial fermentation in the large intestine}

The primary role of the colonic microbiota is to salvage energy from dietary material that has escaped digestion in the upper GI tract, through the process of fermentation. Approximately $8-10 \%$ of the total daily energy requirements of the host are derived from colonic bacterial fermentation (Gibson et al. 2000). Most bacteria in the adult human colon are saccharolytic and so obtain their energy through the fermentation of carbohydrates. Diet is one of the principal factors that determine the type and amount of bacteria that colonise the bowel, as well as regulating metabolic processes. Principal substrates for colonic bacterial growth are dietary ingredients that have escaped digestion in the upper GI tract (Cummings et al. 1987).

The principal products of colonic fermentation are SCFA. It is estimated that $>95 \%$ of the SCFA produced is absorbed through the colonic epithelium, indicating that SCFA can potentially be a source of energy to the host (Cummings \& Macfarlane, 1991). The most predominant SCFA in the human colon are acetate, butyrate and propionate. Acetate and propionate are found in portal blood. Acetate is metabolised systemically (brain, muscle tissues), whereas propionate is cleared by the liver (Salminen et al. 1998). The function of propionate is still not clear; however, it may lower the hepatic synthesis of cholesterol by interfering with its synthesis in the liver (Delzenne \& Kok, 1999). Butyrate is a major source of fuel for the mucosa (colonic epithelium) and has been shown to be involved in mitosis and mucosa regeneration (Cummings, 1981). Butyrate is almost completely consumed by the colonic epithelium. It plays an important role in the metabolism and normal development of colonic epithelial cells (Barcenilla et al. 2000). Lactate, ethanol and succinate are also important products of fermentation; however, they do not accumulate in the lumen as they are utilised by other bacterial species, i.e. act as electron sink products in anaerobic metabolism (Cummings et al. 1987). Another important product of fermentation in the colon is gas, with $\mathrm{H}_{2}$ and $\mathrm{CO}_{2}$ being predominant. Some $\mathrm{H}_{2}$ may be further metabolised to $\mathrm{CH}_{4}$, acetate or $\mathrm{H}_{2} \mathrm{~S}$, while the rest is expelled from the body via flatus.

\section{Gut flora and health}

The human colonic microbiota is a complex and metabolically-active ecosystem that plays a major role in host well-being (Gibson \& Roberfroid, 1995). In addition to its role in metabolic activities that result in salvage of energy and absorbable nutrients, the large intestinal microbiota contributes towards health in a number of other ways. The colonic microbiota is suggested to play an important role in the protection against pathogens, and has important trophic effects on intestinal epithelia and immune structure and function (Guarner, 2006).

Indigenous intestinal bacteria protect the host from infection by exogenous pathogens (Mitsuoka, 1992; Tancrède, 1992) and opportunistic bacteria that are present in the gut (Guarner, 2006). This mechanism of protection is termed colonisation resistance (Macfarlane \& McBain, 1999). The strictly anaerobic components of the microflora appear to be the most crucial to the maintenance of colonisation resistance (van der Waaij, 1999). This equilibrium between species of resident bacteria provides a 'balanced' gut flora that directly influences GI health.

Some indigenous colonic bacteria are thought to be beneficial to health, i.e. lactobacilli and bifidobacteria. Amongst the health-promoting actions of the colonic microbiota are colonisation resistance, facilitation of digestion, production of SCFA, antitoxigenic activity and stimulation of the immune system of the host (Guarner \& Malagelada, 2003). However, a number of factors influence the composition of the microbiota, and may be related to changes in physiological conditions of the host (age, health status, stress etc.), the composition of the diet and environmental circumstances (e.g. use of pharmaceutical compounds such as antibiotics). In this way, the conditions underlying digestion (e.g. $\mathrm{pH}$, substrate availability, transit time, IgA secretion etc.) may be modulated, which could result in a decline of beneficial bacteria and an increase in potentially-harmful bacteria. Some groups are considered benign, such as Eubacterium spp. and methanogens (Gibson, 1998). Additionally, some species are considered to be detrimental for human health. The most important colonic pathogens are probably clostridia, some bacteroides and sulphate-reducing bacteria. They have been associated with the production of toxins (Steer et al. 2001).

\section{Dietary modulation of the gut microbiota}

The concept of a healthy microflora is not a new one and probably originates with Metchnikoff (1907), who suggested that the long and healthy life of Bulgarian peasants was a result of their consumption of fermented milk products. He hypothesised that the complex microbial population in the colon was having an adverse effect on the host through the so-called 'autointoxication' effect. During the last few years the role of the intestinal microflora in health and disease has become increasingly recognised. Much interest exists in modulating the composition of the gut towards a potentially more beneficial community. This outcome may be achieved by using targeted dietary supplementation with functional foods (Collins \& Gibson, 1999). A functional food is a dietary ingredient that has a cellular or physiological effect above basic nutritional value (Gibson, 1998; Playne et al. 2003). Recognition of the health-promoting properties of specific commensal 
micro-organisms has encouraged modulation of the human intestinal microflora towards a more beneficial composition and metabolism, by using probiotics, prebiotics and synbiotics (Gibson \& McCartney, 1998).

\section{Probiotics}

The word 'probiotic' means 'for life' and is derived from the Latin 'pro', which means 'for', and the Greek 'biotikos', which means 'living'. The earliest definition of the term probiotic was given by Parker (1974): 'organisms and substances which contribute to intestinal microbial balance'. This definition was refined by Fuller (1989) to: 'live microbial feed supplements which beneficially affect the host animal by improving its intestinal microbial balance'. Bifidobacteria and lactobacilli are the most popular target micro-organisms for probiotic application. To a lesser extent, certain Gram-positive cocci and yeasts (Saccharomyces) are also used (Rycroft et al. 1999). The most effective probiotic strains for human use have proved to be of human origin (Dunne et al. 2001).

A number of criteria are used to select for probiotic strains. An effective probiotic must be non-pathogenic and non-toxic and exert a beneficial effect on the host. Moreover, they should: be capable of surviving passage through the GI tract, particularly the harsh environmental conditions in the human stomach and small intestine (e.g. gastric acid, bile acid and digestive enzymes), and compete along with a highly-diverse and competitive environment presented by the human gut microflora (Bezkorovainy, 2001; Dunne et al. 2001); adhere to the intestinal epithelial cell lining (as it may increase persistence in the gut) (Guarner \& Schaafsma, 1998); produce antimicrobial substances towards pathogens; remain viable during storage and use; have good sensory properties; be isolated from the same species as its intended use (Goldin, 1998; Collins \& Gibson, 1999). It has been suggested that for a probiotic micro-organism to have any effect in the presence of the human gut microflora it should be ingested at a daily dose of $\geq 10^{7}$ colony-forming units/ml (Donnet-Hughes et al. 1999). However, the quantity required may be strain dependent, target dependent or specific to certain health outcomes or applications.

\section{Probiotics and gastrointestinal health effects}

\section{Lactose intolerance}

Numerous clinical studies have reported positive effects of probiotics in the prevention and/or treatment of several GI diseases and disorders (Nobaek et al. 2000; Wullt et al. 2003; Yamano et al. 2006). Alleviating symptoms of lactose malabsorption was one of the first clinical effects of probiotics to be demonstrated (Gilliland, 1985). Lactose intolerance is common throughout the world and is related to a deficiency of the enzyme $\beta$-galactosidase in the intestinal mucosa. Undigested lactose is clinically manifest by abdominal distension, excessive flatulence and/or profuse watery diarrhoea. Probiotic bacteria (such as lactobacilli and bifidobacteria) increase the production of $\beta$-galactosidase (lactase) concentrations, which can then improve lactose digestibility in the small intestine (Rastall et al. 2000), thus alleviating the symptoms of lactose malabsorption (Marteau et al. 1990; de Vrese et al. 2001).

\section{Constipation}

There is some evidence suggesting that probiotics might relieve constipation. Constipation is a common condition characterised by a slow transit time that results in infrequent bowel movements, small hard faeces or difficult painful defecation, in addition to discomfort, distension and abdominal bloating (Salminen et al. 1998). Children and the elderly are the most affected individuals; however, it can occur as a symptom-based disorder and/or disease (Ouwehand et al. 2002; Banaszkiewicz \& Szajewska, 2005; Fernández-Bañares, 2006). An unbalanced diet is the usual cause of constipation, such as high-risk diets including low-fibre, low-residue and gluten-free diets. Probiotics have been suggested to increase the metabolic activity of colonic microflora in order to improve intestinal motility and reduce faecal enzyme activity (FernándezBañares, 2006). Studies have shown that milk or yoghurt fermented with different probiotics may reduce intestinal transit time and increase the daily stool number in constipated patients (Marteau et al. 2002).

\section{Diarrhoeal studies}

A number of clinical studies have demonstrated the efficacy of probiotics in the treatment and/or prevention of diarrhoea (Guarino et al. 1997; D'Sousa et al. 2002). Diarrhoea occurs in about $20 \%$ of patients who receive antibiotics (Marteau et al. 2001). Antibiotics may directly affect the indigenous gut microbiota by compromising colonisation resistance and favouring the growth of pathogenic micro-organisms, such as Clostridium difficile. Randomised controlled trials have shown a marked therapeutic effect of probiotics to reduce the incidence of diarrhoea caused by $C$. difficile (Wullt et al. 2003; Plummer et al. 2004). In a study by Gorbach et al. (1987) Lactobacillus rhamnosus GG (LGG) was shown to reduce episodes of relapsing diarrhoea caused by $C$. difficile toxin in five patients. LGG was also found to decrease toxin levels in faeces of the patients. LGG has been shown to lower the rate of diarrhoea in Finns travelling to Turkey (Oksanen et al. 1990) and Americans travelling to developing countries (Hilton et al. 1997). LGG has also been reported to reduce the duration of acute rotaviral diarrhoea in children. In a group of children hospitalised because of severe diarrhoea and randomised into two groups, one receiving a placebo and the other given LGG (Isolauri et al. 1991), the duration of diarrhoea was reduced for the group given LGG compared with the placebo group. Moreover, the number of intestinal immunoglobulin-secreting cells in the group given LGG was almost twice that in the placebo group for $\operatorname{IgM}, \operatorname{IgA}$ and $\operatorname{IgG}$ isotopes. These studies demonstrate that a probiotic approach can be effective in treating antibiotic-induced diarrhoea, traveller's diarrhoea (most likely of mixed bacterial and viral aetiology) 
and diarrhoeal disease in young children (predominantly caused by rotavirus).

\section{Atopic diseases and food allergy}

Probiotics have also been reported to help prevent and/or manage atopic diseases (i.e. eczemas) and food allergies (e.g. cow's milk allergy) in infants. Immaturity of the immune system and the GI barrier may explain the peak prevalence of food allergies in infancy (Salminen et al. 1998). LGG and other lactobacilli are reported to hydrolyse purified casein to smaller peptides and amino acids and hence decrease the proliferation of mitogen-induced human lymphocytes compared with non-treated caseins (Sutas et al. 1996). Majamaa \& Isolauri (1997) have studied the effects of LGG supplementation for infants with atopic eczema and have found a reduction in the extent and intensity of atopic dermatitis. Several other studies have shown the potential of probiotics in the management and prevention of atopic disease, including the use of probiotics by pregnant mothers being suggested to confer protection to the unborn infant (Isolauri et al. 2000; Kalliomäki et al. 2003).

\section{Mechanisms of probiotic activity}

Although there is good evidence for the effect of probiotic preparations in GI health, little is known about the manner in which these changes occur. Several different mechanisms by which probiotics may protect the host from intestinal disorders have been suggested:

1. production of anti-microbial substances: lactic acid bacteria produce a wide variety of anti-bacterial substances, as well as inhibitory metabolites such as organic acids, diacetyl and $\mathrm{H}_{2} \mathrm{O}_{2}$. They also produce bacteriocins and antibiotic-like substances with activity against both Gram-positive and Gram-negative bacteria (Rolfe, 2002);

2. competition for adhesion receptors or sites: the presence of some bacteria in the intestinal tract is dependent on their ability to adhere to the gut epithelium, such that they become immobilised on the gut wall and resist being flushed out by peristalsis, as well as occupying a niche at the expense of potentiallyharmful organisms (Fuller, 1992; Fooks \& Gibson, 2002);

3. competition for nutrients;

4. stimulation of immunity: the underlying mechanisms of immune stimulation are not well understood, but specific cell-wall components or cell layers may act as an adjuvant and increase humoral immune response;

5. degradation of toxin receptors.

Probiotic supplementation in infant formulas has shown that some strains may persist in the infant gut (Bennet et al. 1992; Millar et al. 1993) and lower stool pH (Langhendries et al. 1995). Supplementation with LGG (Isolauri et al. 1991) and with Bifidobacterium bifidum and Streptococcus thermophilus (Saavedra et al. 1994) have been successful in preventing rotavirus diarrhoea in infants. The LGG strain has also been well researched for its probiotic effects in reducing atopic eczema (see Majamaa \& Isolauri, 1997; Isolauri et al. 2000; Kalliomäki et al. 2003).

\section{Prebiotics}

An alternative approach to probiotics for intestinal flora modulation is the use of prebiotics. A prebiotic is 'a nondigestible food ingredient that beneficially affects the host by selectively stimulating the growth and/or activity of one or a limited number of bacterial species already resident in the colon' (Gibson \& Roberfroid, 1995). For a food ingredient to be classified as a prebiotic, it must: (1) neither be hydrolysed nor absorbed in the upper part of the GI tract; (2) be a selective substrate for one or a few beneficial bacteria in the colon (e.g. lactobacilli and bifidobacteria); (3) consequently be able to alter the colonic microflora towards a healthier composition (Gibson \& Roberfroid, 1995). The premise behind prebiotics is therefore to stimulate certain indigenous bacteria resident in the gut rather than introducing exogenous species, as is the case with probiotics. Ingesting a diet containing non-digestible carbohydrates that are selectively fermented by indigenous beneficial bacteria is the prebiotic principle. Any dietary component that reaches the colon intact is a potential prebiotic; however, most of the interest in the development of prebiotics is aimed at non-digestible oligosaccharides. These oligosaccharides are considered to be the most important prebiotic substrates because they meet all the current criteria for prebiotic classification (Rycroft et al. 1999). Oligosaccharides are sugars consisting of between approximately two and twenty saccharide units, i.e. they are short-chain polysaccharides. Apart from those that occur naturally in fruits and vegetables, and are extractable, others can be commercially produced by the hydrolysis of polysaccharides (e.g. dietary fibres, starch) or through enzymic generation.

As prebiotics exploit the use of non-viable dietary components to improve gut health, the range of foods into which they can be added is much wider than that for probiotics, where culture viability needs to be maintained. The prebiotic approach has the advantage that heat stability or exposure to $\mathrm{O}_{2}$ is not an issue and it is concentrated towards stimulation or enhancement of the indigenous probiotic flora. Hence, for practical as well as aesthetic reasons their use in formula feeds currently seems to be more widespread than the use of probiotics. The targeted health benefits are similar.

Lactulose, a bifidogenic substrate (Tuohy et al. 2002), was used as an adjunct to formula feeds in the 1950s (Gibson et al. 2000). However, today it is not used as a foodstuff because it is not licensed as such, because of its laxation effect at high doses. Two non-digestible oligosaccharides currently used in infant formulas are the fructo-oligosaccharides and galacto-oligosaccharides. There are a number of studies supporting beneficial effects on the adult human intestinal microflora of fructooligosaccharides (Gibson \& Roberfroid, 1995; Bouhnik et al. 1999) and galacto-oligosaccharides (Tanaka et al. 1983; Bouhnik et al. 1997; Sako et al. 1999). 
It is likely that inclusion of such dietary prebiotic components in moderate amounts may benefit formula-fed infants by establishing an intestinal flora with more bifidobacteria and less-harmful bacteria. The health aspects of this approach have not yet been determined.

\section{Synbiotics}

A further possibility in microflora management is the use of synbiotics, the combination of probiotics and prebiotics. A synbiotic has been defined as 'a mixture of probiotics and prebiotics that beneficially affects the host by improving the survival and implantation of live microbial dietary supplements in the GI tract, by selectively stimulating the growth and/or activating the metabolism of one or a limited number of health-promoting bacteria, and thus improving host welfare' (Gibson \& Roberfroid, 1995). However, they have not yet entered the infant food market.

\section{Conclusion}

The intestinal microbiota forms a diverse and complex ecosystem. However, there is much variability in bacterial numbers and populations between the stomach, small intestine and colon. In comparison with other regions of the GI tract, the human colon is an extremely-denselypopulated microbial ecosystem. The large gut microflora is acquired at birth. Initially, facultatively-anaerobic strains such as Escherichia coli dominate. Thereafter, differences exist in the species composition that develops, which is largely governed by the type of diet. The faecal flora of breast-fed infants is dominated by populations of bifidobacteria, and comprises only about $1 \%$ enterobacteria. It is thought that certain bifidogenic factors are present in human breast milk. In contrast, formula-fed infants have a more complex microbiota, with bifidobacteria, bacteroides, clostridia and streptococci all being prevalent. After weaning, a pattern that resembles the adult flora becomes established. This critical stage of development is likely to affect health status in later life. Microflora modulation can occur through diets that contain probiotics and/or prebiotics, and is applicable to use in infant feeds.

\section{References}

Banaszkiewicz A \& Szajewska H (2005) Ineffectiveness of Lactobacillus GG as an adjunct to lactulose for the treatment of constipation in children: a double-blind, placebo-controlled randomized trial. Journal of Pediatrics 146, 364-369.

Barcenilla A, Pryde SE, Martin JC, Duncan SH, Stewart CS, Henderson C \& Flint HJ (2000) Phylogenetic relationships of butyrate-producing bacteria from the human gut. Applied and Environmental Microbiology 66, 1654-1661.

Bennet R, Nord CE \& Zetterstrom R (1992) Transient colonisation of the gut of newborn infants by orally administered bifidobacteria and lactobacilli. Acta Paediatrica 81, 784-787.

Benno Y, Sawada K \& Mitsuoka T (1984) The intestinal microflora of infants: composition of faecal flora in breast-fed and bottle-fed infants. Microbiology and Immunology 28, 975-986.

Bezkorovainy A (2001) Probiotics: determinants of survival and growth in the gut. American Journal of Clinical Nutrition 73, 399S-405S.
Bouhnik Y, Flourie B, D'Agay-Abensour L, Pochart P, Gramet G, Durand M \& Rambaud JC (1997) Administration of trans-galacto-oligosaccharides increases fecal bifidobacteria and modifies colonic fermentation metabolism in healthy humans. Journal of Nutrition 127, 444-448.

Bouhnik Y, Vahedi K, Achour L, Attar A, Salfati J, Pochart P, Marteau P, Flourie B, Bornet F \& Rambaud JC (1999) Shortchain fructo-oligosaccharide administration dose-dependently increases fecal bifidobacteria in healthy humans. Journal of Nutrition 129, 113-116.

Collins MD \& Gibson GR (1999) Probiotics, prebiotics, and synbiotics: approaches for modulating the microbial ecology of the gut. American Journal of Clinical Nutrition 69, 1052S$1057 \mathrm{~S}$.

Cummings JH (1981) Short chain fatty acids in the human colon. Gut 22, 763-779.

Cummings JH \& Macfarlane GT (1991) The control and consequences of bacterial fermentation in the human colon. Journal of Applied Bacteriology 70, 443-459.

Cummings JH, Pomare EW, Branch WJ, Naylor CPE \& Macfarlane GT (1987) Short chain fatty acids in human large intestine, portal hepatic and venous blood. Gut 28, 1221-1227.

Cuthbertson WJF (1999) Evolution of infant nutrition. British Journal of Nutrition 81, 359-371.

Delzenne NM \& Kok NN (1999) Biochemical basis of oligofructose-induced hypolipidaemia in animal models. Journal of Nutrition 129, 1467S-1470S.

de Vrese M, Stegelmann A, Richter B, Fenselau S, Laue C \& Schrezenmeir J (2001) Probiotics - compensation for lactose insufficiency. American Journal of Clinical Nutrition 73, Suppl. 2, 421S-429S.

Donnet-Hughes A, Rochat F, Serrant P, Aeschlimann JM \& Schiffrin EJ (1999) Modulation of nonspecific mechanisms of defense by lactic acid bacteria: effective dose. Journal of Dairy Science 82, 863-869.

Drasar BS \& Barrow PA (1985) Intestinal Microbiology. London: Van Nostrand Reinhold Co. Ltd.

D’Sousa A, Rajkumar C, Cooke J \& Bulpitt CJ (2002) Probiotics in prevention of antibiotic associated diarrhoea: meta-analysis. British Medical Journal 324, 1361-1364.

Dunne C, O'Mahony L, Murphy L, Thornton G, Morrissey D, O'Halloran S et al. (2001) In vitro selection criteria for probiotic bacteria of human origin: correlation with in vivo findings. American Journal of Clinical Nutrition 73, 386S-392S.

Fernández-Bañares F (2006) Nutritional care of the patient with constipation. Best Practice and Research Clinical Gastroenterology 20, 575-587.

Fooks LJ \& Gibson GR (2002) Probiotics as modulators of the gut flora. British Journal of Nutrition 88, S39-S49.

Fuller R (1989) Probiotics in man and animals. Journal of Applied Bacteriology 66, 365-378.

Fuller R (1992) The effect of probiotics on the gut micro-ecology of farm animals. In The Lactic Acid Bacteria in Health and Disease, vol. 1, pp. 171-192 [BJB Wood, editor]. Cambridge: Elsevier Science Publishers Ltd.

Garofalo RP \& Goldman AS (1999) Expression of functional immunomodulatory and anti-inflammatory factors in human milk. Clinics in Perinatology 26, 361-377.

Gauhe A, Gyorgy P, Hoover JR, Kuhn R, Rose CS, Ruelis HW \& Zilliken F (1954) Bifidus factor - preparation obtained from human milk. Archives of Biochemistry 49, 214-224.

Gibson GR (1998) Dietary modulation of the human gut microflora using probiotics. British Journal of Nutrition $\mathbf{8 0}$, S209-S212.

Gibson GR, Berry-Ottaway P \& Rastall RA (2000) Probiotics: New Developments in Functional Foods. Oxford: Chandos Publishing Ltd. 
Gibson GR \& McCartney AL (1998) Modification of the gut flora by dietary means. Biochemical Society Transactions 26, 222-228.

Gibson GR \& Roberfroid MB (1995) Dietary modulation of the human colonic microflora introducing the concept of probiotics. Journal of Nutrition 125, 1401-1412.

Gilliland SE (1985) Influence of bacterial starter cultures on nutritional value of foods: improvement of lactose digestion by consuming foods containing lactobacilli. Cultured Dairy Products Journal 20, 28-33.

Goldin BR (1998) Health benefits of probiotics. British Journal of Nutrition 80, S203-S207.

Goldman AS, Chheda S \& Garofalo R (1997) Spectrum of immunomodulating agents in human milk. International Journal of Pediatric Hematology/Oncology 4, 491-497.

Gorbach SL, Chang TW \& Goldin B (1987) Successful treatment of relapsing Clostridium difficile colitis with Lactobacillus GG. Lancet ii, 1519.

Guarino A, Canani RB, Spagnuolo MI, Albano F \& Benedetto LD (1997) Oral bacterial therapy reduces the duration of symptoms and of viral excretion in children with mild diarrhoea. Journal of Pediatric Gastroenterology and Nutrition 25, 516-519.

Guarner F (2006) Enteric flora in health and disease. Digestion 73, 5-12.

Guarner F \& Malagelada JR (2003) Gut flora in health and disease. Lancet 361, 512-519.

Guarner F \& Schaafsma GJ (1998) Probiotics. International Journal of Food Microbiology 39, 237-238.

Harmsen HJM, Wildeboer-Veloo ACM, Grijpstra J, Knol J, Degener JE \& Welling GW (2000) Development of $16 \mathrm{~S}$ rRNA-based probes for the Coriobacterium group and the Atopobium cluster and their application for enumeration of Coriobacteriaceae in human faeces from volunteers of different age groups. Applied and Environmental Microbiology 66, 4523-4527.

Hilton E, Kolakowski P, Singer C \& Smith M (1997) Efficacy of Lactobacillus GG as a diarrheal preventive in travellers. Journal of Travel Medicine 4, 41-43.

Holzapfel WH, Haberer P, Snel J, Schillinger U \& Huis in't Veld $\mathrm{JH}$ (1998) Overview of gut flora and probiotics. International Journal of Food Microbiology 41, 85-101.

Isolauri E, Arvola T, Sütas Y, Moilanen E \& Salminen S (2000) Probiotics in the management of atopic eczema. Clinical and Experimental Allergy 30, 1604-1610.

Isolauri E, Juntunen M, Rautanen T, Sillanaukee P \& Koivula T (1991) A human Lactobacillus strain (Lactobacillus casei strain GG) promotes recovery from acute diarrhea in children. Pediatrics 88, 90-97.

Kalliomäki M, Salminen S, Poussa T, Arvilommi H \& Isolauri E (2003) Probiotics and prevention of atopic disease: 4-year follow-up a randomised placebo-controlled trial. Lancet 361, 1869-1871.

Kimura K, McCartney AL, McConnell MA \& Tannock GW (1997) Analysis of fecal populations of bifidobacteria and lactobacilli and investigation of the immunological responses of their human hosts to the predominant strains. Applied and Environmental Microbiology 63, 3394-3398.

Kunz C, Rudloff S, Baier W, Klein N \& Strobel S (2000) Oligosaccharides in human milk: structural, functional, and metabolic aspects. Annual Review of Nutrition 20, 699-722.

Langhendries JP, Detry J, Van Hees J, Lamboray JM, Darimont J, Mozin MJ, Secretin MC \& Senterre J (1995) Effect of a fermented infant formula containing viable bifidobacteria on the fecal flora composition and $\mathrm{pH}$ of healthy full-term infants. Journal of Pediatric Gastroenterology and Nutrition 2, 177181.
Macfarlane GT \& McBain AJ (1999) The human colonic microbiota. In Colonic Microbiota, Nutrition and Health, pp. 1-25 [GR Gibson and MB Roberfroid, editors]. Dordrecht, The Netherlands: Kluwer Academic Publishers.

Majamaa H \& Isolauri E (1997) Probiotics: a novel approach in the management of food allergy. Journal of Allergy and Clinical Immunology 99, 179-185.

Marteau P, Cuillerier E, Meance S, Gerhardt MF, Myara A, Bouvier M, Bouley C, Tondu F, Bommelaer G \& Grimaud JC (2002) Bifidobacterium animalis strain DN-173 010 shortens the colonic transit time in healthy women: a double-blind, randomized, controlled study. Alimentary Pharmacology and Therapeutics 16, 587-593.

Marteau P, de Vrese M, Cellier CJ \& Schrezenmeir J (2001) Protection from gastrointestinal diseases with the use of probiotics. American Journal of Clinical Nutrition 73, Suppl. 2, 430S-436S

Marteau P, Pochart P, Flourié B, Pellier P, Santos L, Desjeux JF \& Rambaud JC (1990) Effect of chronic ingestion of a fermented dairy product containing Lactobacillus acidophilus and Bifidobacterium bifidum on metabolic activities of the colonic flora in humans. American Journal of Clinical Nutrition 52, 685-688.

Metchnikoff E (1907) The prolongation of life. Dairy Science 36, 656.

Millar MR, Bacon C, Smith SL, Walker V \& Hall MA (1993) Enteral feeding of premature infants with Lactobacillus GG. Archives of Disease in Childhood 69, 483-487.

Mitsuoka T (1992) Intestinal flora and aging. Nutrition Reviews 50, 438-446.

Nobaek S, Johansson ML, Molin G, Ahrné S \& Jeppsson B (2000) Alteration of intestinal microflora is associated with reduction in abdominal bloating and pain in patients with irritable bowel syndrome. American Journal of Gastroenterology 95, 1231-1238.

Mountzouris KC, McCartney AL \& Gibson GR (2002) Intestinal microflora of human infants and current trends for its nutritional modulation. British Journal of Nutrition 87, 405-420.

Oksanen PJ, Salminen S, Saxelin M, Hamalainen P, IhantolaVormisto A, Muurasniemi-Isoviita L, Nikkari S, Oksanen T, Porsti I \& Salminen E (1990) Prevention of travellers' diarrhoea by Lactobacillus GG. Annals of Medicine 22, 53-56.

Ouwehand AC, Lagstrom H, Suomalainen T \& Salminen S (2002) Effect of probiotics on constipation, fecal azoreductase activity and fecal mucin content in the elderly. Annals of Nutrition and Metabolism 46, 159-162.

Parker RB (1974) Probiotics, the other half of the antibiotic story. Animal Nutrition Health 29, 4-8.

Petschow BW \& Talbott RD (1991) Response of Bifidobacterium species to growth promoters in human and cow milk. Pediatric Research 29, 208-213.

Playne MJ, Bennett LE \& Smithers GW (2003) Functional dairy foods and ingredients. Australian Journal of Dairy Technology 58, 242-264.

Plummer S, Weaver MS, Harris JC, Dee P \& Hunter J (2004) Clostridium difficile pilot study: effects of probiotic supplementation on the incidence of $C$. difficile diarrhoea. International Microbiology 7, 59-62.

Rastall RA, Fuller R, Gaskins HR \& Gibson GR (2000) Colonic functional foods. In Functional Foods, pp. 71-89 [GR Gibson and CM Williams, editors]. Cambridge: Woodhead Publishing Limited.

Rolfe RD (2002) The role of probiotic cultures in the control of gastrointestinal health. Journal of Nutrition 130, 396S-402S.

Rotimi VO \& Duerden BI (1981) The development of the bacterial flora in normal neonates. Journal of Medical Microbiology 14, 51-62. 
Rycroft CE, Fooks LJ \& Gibson GR (1999) Methods for assessing the potential of prebiotics and probiotics. Current Opinion in Clinical Nutrition and Metabolic Care 2, 1-4.

Saavedra JM, Bauman NA, Oung I, Perman JA \& Yolken RH (1994) Feeding of Bifidobacterium bifidum and Streptococcus thermophilus to infants in hospital for prevention of diarrhoea and shedding of rotavirus. Lancet 344, 1046-1049.

Sako T, Matsumoto K \& Tanaka R (1999) Recent progress on research and applications of non-digestible galactooligosaccharides. International Dairy Journal 9, 69-80.

Salminen S, Bouley C, Boutron-Ruault MC, Cummings JH, Franck A, Gibson GR, Isolauri E, Moreau MC, Roberfroid M \& Rowland I (1998) Functional food science and gastrointestinal physiology and function. British Journal of Nutrition 80, S147-S171.

Stark PL \& Lee A (1982) The microbial ecology of the large bowel of breast-fed and formula-fed infants during the first year of life. Journal of Medical Microbiology 15, 189-203.

Steer T, Carpenter H, Tuohy K \& Gibson GR (2001) Perspectives on the role of the human gut microflora in health and disease and its modulation by pro- and prebiotics. Nutrition Research Reviews 13, 229-254.

Sutas Y, Hurme M \& Isolauri E (1996) Down-regulation of anti-CD3 antibody-induced IL-4 production by bovine caseins hydrolysed with Lactobacillus GG-derived enzymes. Scandinavian Journal of Immunology 43, 687-689.
Tanaka R, Takayama H, Morotomi M, Kuroshima T, Ueyama S, Matsumoto K, Kuroda A \& Mutai M (1983) Effects of administration of TOS and Bifidobacterium breve 4006 on the human fecal flora. Bifidobacteria Microflora 2, 17-24.

Tancrède C (1992) Role of human microflora in health and disease. European Journal of Clinical Microbiological and Infectious Diseases 11, 1012-1015.

Tuohy KM, Ziemer CJ, Klinder A, Knobel Y, Pool-Zobel BL \& Gibson GR (2002) A human volunteer study to determine the prebiotic effects of lactulose powder on human colonic bacteria. Microbial Ecology in Health and Disease 14, 165173.

van der Waaij D (1999) Microbial ecology of the intestinal microflora: influence of interactions with the host organism. In Probiotics, Other Nutritional factors, and Intestinal Microflora, vol. 42, pp. 1-16 [LA Hanson and RH Yolken, editors]. Philadelphia, PA: Vevey/Lippincott-Raven Publishers.

Wullt M, Hagslätt MLJ \& Odenholt I (2003) Lactobacillus plantarum $299 \mathrm{v}$ for the treatment of recurrent Clostridium difficile-associated diarrhoea: a double-blind, placebo-controlled trial. Scandinavian Journal of Infectious Disease 35, 365-367.

Yamano T, Lino H, Takada M, Blum S, Rochat F \& Fukushima Y (2006) Improvement of the human intestinal flora by ingestion of the probiotic strain Lactobacillus johnsonii La1. British Journal of Nutrition 95, 303-312. 